\title{
Growth and characterization of propyl-para-hydroxybenzoate single crystals
}

\author{
N KARUNAGARAN ${ }^{1}$, P RAMASAMY ${ }^{1, *}$ and R PERUMAL RAMASAMY ${ }^{2}$ \\ ${ }^{1}$ Centre for Crystal Growth, SSN College of Engineering, Kalavakkam 603 110, India \\ ${ }^{2}$ Department of Physics, Anna University, Chennai 600 025, India
}

MS received 4 January 2013; revised 8 March 2013

\begin{abstract}
Single crystals of propyl-p-hydroxybenzoate have been grown by slow evaporation solution technique. The structure of the compound was confirmed by FT-IR, FT-Raman spectroscopy and single crystal X-ray diffraction studies. The crystalline perfection of the grown single crystals has been analysed by high resolution X-ray diffraction measurements. Optical properties of the grown single crystals were studied by UV-Vis NIR spectrum. The luminescence behaviour of the single crystal has been analysed by photoluminescence analysis and found maximum luminescence in the lower wavelength region. A simple interferometric technique was used for measuring birefringence of the crystal. The laser damage threshold of the crystal is $1.3 \mathrm{GW} / \mathrm{cm}^{2}$. The mechanical strength of the grown crystal is measured using Vickers microhardness tester. The dielectric properties have been investigated.
\end{abstract}

Keywords. Crystal growth; high-resolution X-ray diffraction; optical properties; luminescence; birefringence.

\section{Introduction}

Study of optical spectra of nanomaterials has been an active area in research due to their good thermal, chemical and luminescence properties. Owing to their low vibrational frequency, these nanomaterials have promising applications in photoluminescence, solid-state lasers, optical fibres and scintillators. There is a need for a broad number of approaches to control the sizes and morphologies of nanoscale inorganic crystals (Abdul Kareem Parchur et al 2011; Parchur et al 2012a,b). However, in the recent past, organic single crystals constructed by $\pi$-conjugated molecules have attracted great attention in the field of organic optoelectronic materials (Pope et al 1963; Avanesjan et al 1974; Fichou et al 1997; Briseno et al 2006). The academic motivation for organic singlecrystal research is their definite structures, which provide a model to investigate the basic interactions between the molecules (supramolecular interaction) and the relationship between molecular stacking modes and optoelectronic performance (luminescence and carrier mobility) (Xie et al 2001, 2005; Reese and Bao 2006; Mannsfeld et al 2007). Meanwhile, the superiorities of organic crystals such as high thermal stability, high ordered structure and high carrier mobility make them attractive candidates for optoelectronic devices such as optically pumped lasers

*Author for correspondence (ramasamyp@ssn.edu.in, proframasamy@hotmail.com)
(Xie et al 2001; Ichikawa et al 2003), field-effect transistors (Butko et al 2003; De Boer et al 2004; Sundar et al 2004), electroluminescence (Hisao et al 2002; Musubu et al 2005; Kok et al 2006) and photovoltaic cell (Tseng et al 2008). Optically pumped laser action has been demonstrated in a broad range of conjugated polymers and oligomers (Hide et al 1996; Tessler et al 1996; Berggren et al 1997; Tessler et al 1999). However, for the electrically driven organic lasers, there still exist many problems to be resolved. One of them is that the lightemitting diodes (LEDs) are damaged before the injected current reaches the threshold value to obtain the laser (about $\mathrm{kA} / \mathrm{cm}^{2}$ ) due to the low charge carrier mobility of the disordered amorphous materials. In the view of current injection and transport, single crystalline organic semiconductors are promising materials for electrically driven organic lasers because their inherent long-range structural ordering could effectively avoid excitons annihilations resulting in the sharp decrease of luminescence quantum efficiency under the high current densities (Takenobu et al 2008). The cutoff wavelength extends to $304 \mathrm{~nm}$. Fluorescent materials, particularly blue fluorescent materials, have been of intense interest because it is one of the key colour components required for full-colour electroluminescence displays and blue fluorescent materials are still rare (Fang et al 2009). Previously, we have reported the growth and some preliminary characterizations of propyl-para-hydroxybenzoate (PHB) single crystal (Karunagaran and Ramasamy 2012). In the present work, we report FT-IR, FT-Raman, single crystal XRD, powder 
XRD, HRXRD, etching analysis, UV-Vis NIR spectrum, photoluminescence, birefringence, laser damage threshold, Vickers microhardness, dielectric studies and thermal analysis.

\section{Experimental}

\subsection{Solubility study and growth of PHB single crystals}

Low-temperature solution growth is the simplest and, in many cases, the least expensive method for production of optical crystals. The commercially available PHB is used for growth. The PHB single crystals have been grown using slow evaporation solution growth technique at room temperature. In order to get good-quality crystals, the PHB material was recrystallized several times before use for growth. The saturation solution of PHB was obtained by dissolving the charge material into the methanol solvent with continuous stirring of the solution at room temperature and this solution was filtered using a Whatman 41 grade filter paper to remove the suspended impurities. The beaker containing the filtered solution was optimally closed for controlled evaporation. We also can control the volatilization rate of solvents through drilling a certain number of pores on the air-tight cover.

Recrystallized salt was used for the solubility studies. Solubility of PHB in methanol was determined by dissolving the solute in methanol taken in an air-tight container maintained at a constant temperature with continuous stirring. After attaining saturation, the equilibrium concentration of the solute was analysed gravimetrically. The solubility of the PHB as a function of temperature $\left(20-40^{\circ} \mathrm{C}\right)$ in methanol was determined and shown in figure $1(\mathrm{a})$. The PHB single crystal of dimension up to $27 \times 16 \times 8 \mathrm{~mm}^{3}$ has been grown for a period of 18 days at room temperature, as shown in figure $1(\mathrm{~b})$.

\subsection{Material characterization techniques}

FT-IR spectroscopy analysis was carried out in the region of $4000-450 \mathrm{~cm}^{-1}$ by $\mathrm{KBr}$ pellet technique using 'Perkin Elmer spectrometer'. The crystal structure was determined by single-crystal X-ray diffraction studies using ENRAF NONIUS CAD4 single-crystal X-ray diffractometer. The data were integrated using BRUKER SAINT; corrections for absorption and decay were applied using BRUKER SAINT. The crystal structure was solved by using the SHELXS-97 program and refined by the SHELXS-97 program (Sheldrick 1997) to an $R$-value of $0 \cdot 0522$. The ORTEP drawing was performed with the ORTEP-3 program (Farrugia 1999). Powder X-ray diffraction pattern was recorded using Rich Seifert X-ray diffractometer employing $\mathrm{CuK} \alpha$ (1.54058 $\AA$ ) radiation, scanning angle ranging from 10 to $70^{\circ}$ at a scan
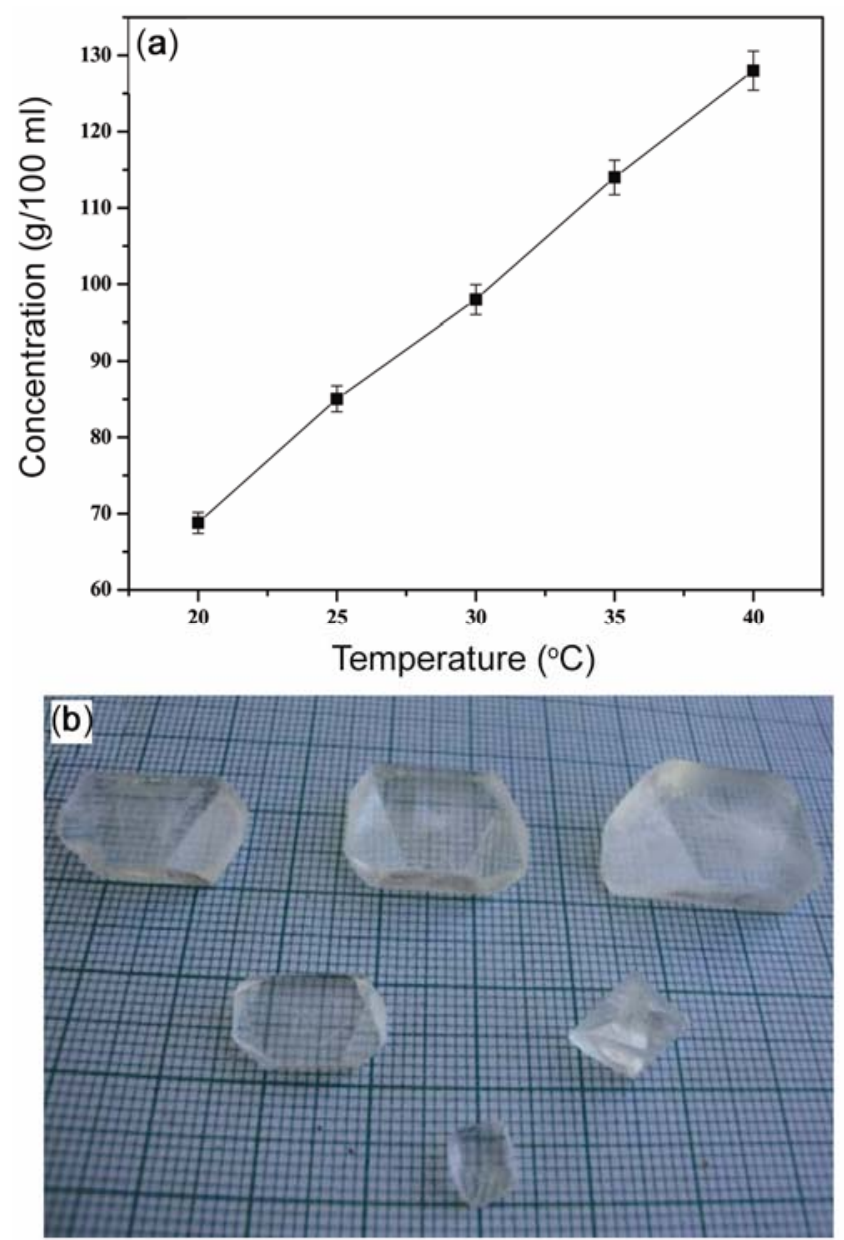

Figure 1. (a) Solubility curve. (b) As-grown PHB single crystals.

rate of $1 \% / \mathrm{min}$ to study the crystallinity of the grown PHB crystal. The surface of the sample was etched in the etching solution (methanol) at room temperature and placed on optical microscope (Olympus U-TV0.5XC-3, Japan). The transmittance of the grown PHB single crystal of $3 \mathrm{~mm}$ thickness was measured by Perkin-Elmer Lambda 35 spectrophotometer for the wavelength range of 200$1100 \mathrm{~nm}$ with slit width $2 \mathrm{~nm}$ and scan speed $240 \mathrm{~nm} / \mathrm{min}$ at room temperature. Photoluminescence emission spectrum was recorded at room temperature, using 'Horiba Jobin-Yvon Fluoromax 4' spectrofluorometer. Using LCR meter, the capacitance of the crystal was measured for the frequency of $1 \mathrm{kHz}$ at different temperatures. The laser-induced damage studies have been carried out for the PHB single crystal. The samples used were carefully selected from the grown ingots with best quality by visual observation. Nd: YAG laser operating at $1064 \mathrm{~nm}$ was used at $5 \mathrm{~Hz}$ with the pulse width $30 \mathrm{~ns}$. TG/DTA analysis of PHB single crystal was carried out from 25 to $500{ }^{\circ} \mathrm{C}$ at a heating rate of $10^{\circ} \mathrm{C} / \mathrm{min}$ using NETZSCH STA 409 $\mathrm{C} / \mathrm{CD}$ in the nitrogen atmosphere. 


\section{Results and discussion}

\subsection{FT-IR and FT-Raman spectrum analysis}

The importance of hydrogen bonding in the packing of p-hydroxybenzoate molecules in the crystal lattice is greatly evident by the broadened envelope due to phenolic O-H stretch around $3271 \mathrm{~cm}^{-1}$. The peaks at 2980 and $2893 \mathrm{~cm}^{-1}$ are due to $\mathrm{C}-\mathrm{H}$ of methyl asymmetric and methyl symmetric stretching. The peak at $1677 \mathrm{~cm}^{-1}$ is due to $\mathrm{C}=\mathrm{O}$ stretching of ester. The peaks at 1588, 1605 and $1677 \mathrm{~cm}^{-1}$ are due to $\mathrm{C}=\mathrm{C}$ aromatic stretching. The peak at $1321 \mathrm{~cm}^{-1}$ is due to $\mathrm{C}-\mathrm{O}$ stretching. The peak at $1280 \mathrm{~cm}^{-1}$ is due to $\mathrm{C}-\mathrm{O}$ stretch of alkane chain. The peak at $1225 \mathrm{~cm}^{-1}$ is due to $\mathrm{C}-\mathrm{C}$ aliphatic stretching. The peaks at 849,773 and $697 \mathrm{~cm}^{-1}$ are due to aromatic $\mathrm{C}-\mathrm{H}$ stretching (figure 2a).

The presence of various functional groups was further confirmed by Raman spectrum as shown in figure 2(b). In the higher wavelength region, there is a peak at $3083 \mathrm{~cm}^{-1}$, which is due to $\mathrm{O}-\mathrm{H}$ aromatic stretching vibration. The peaks at 1326 and $877 \mathrm{~cm}^{-1}$ are due to aromatic $\mathrm{C}-\mathrm{H}$ in-plane bending and out-of-plane bending vibrations,
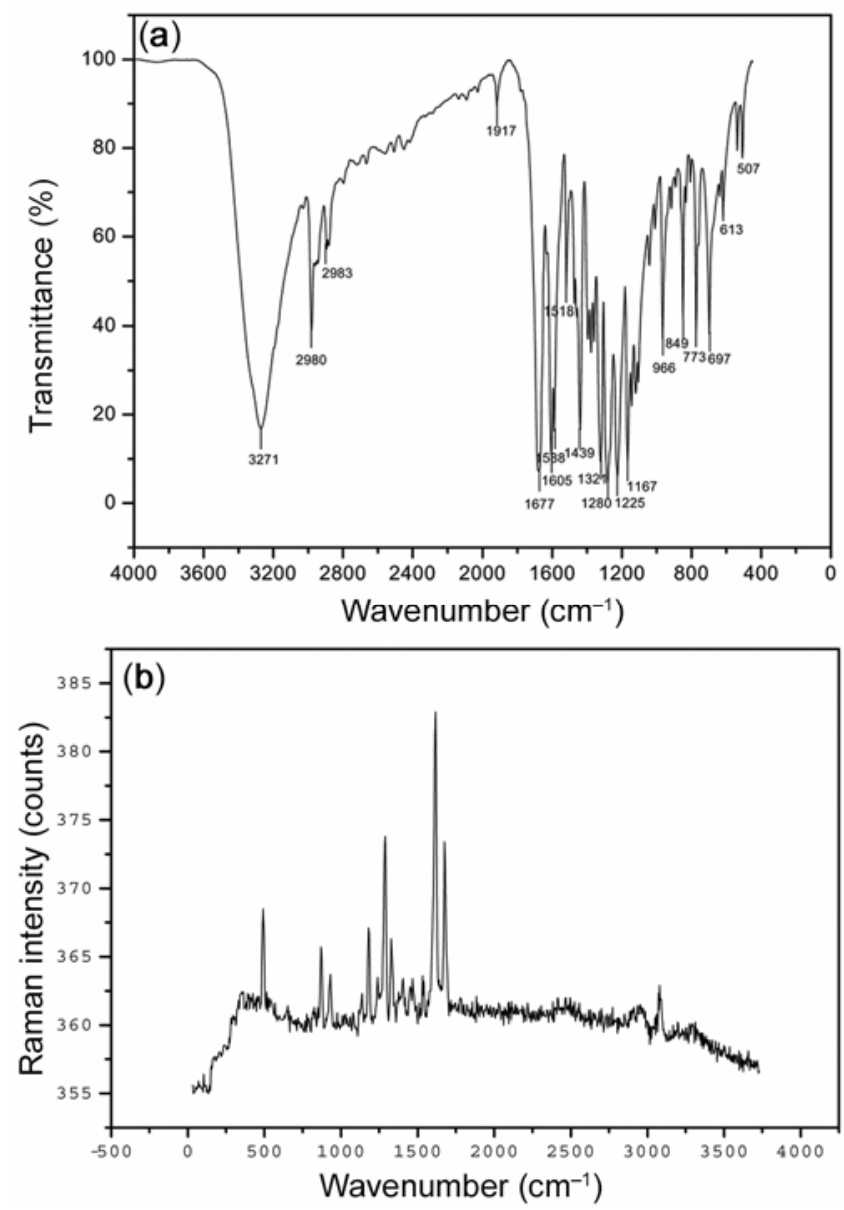

Figure 2. (a) FT-IR spectrum and (b) FT-Raman spectrum. respectively. The $\mathrm{C}=\mathrm{O}$ stretching vibration assigned at $1624 \mathrm{~cm}^{-1}$ is in the double-bond region. The peaks at 1286 and $492 \mathrm{~cm}^{-1}$ are due to $\mathrm{C}-\mathrm{O}$ stretching vibration and $\mathrm{C}-\mathrm{O}$ out-of-plane bending deformation, respectively.

\subsection{Single-crystal $X$-ray diffraction studies}

The single-crystal X-ray diffraction study shows that PHB belongs to monoclinic crystal system $P 2_{1} / c$ space group with the lattice parameters, $a=12.025 \AA$, $b=13.802 \AA, c=11.762 \AA$ and $\alpha=90^{\circ}, \beta=108.61^{\circ}$, $\gamma=90^{\circ}$, which are in good agreement with the reported values (Ferdinando Giordano et al 1999). Figure 3 shows the ORTEP view of the molecule.

\subsection{Powder X-ray diffraction}

The grown crystals were subjected to powder X-ray diffraction. From the diffraction pattern, $h k l$ values for each diffraction peak in the corresponding spectrum of sample were identified. The observed prominent peaks of PHB are (11-1), (11-2), (20-2), (201), (130), (20-3), (31-2), (202), (103), (242), (510) and (42-5) as shown in figure 4 .

\subsection{High-resolution $X$-ray diffraction}

To evaluate the crystalline perfection of the PHB crystal, high-resolution X-ray diffraction (HRXRD) analysis was

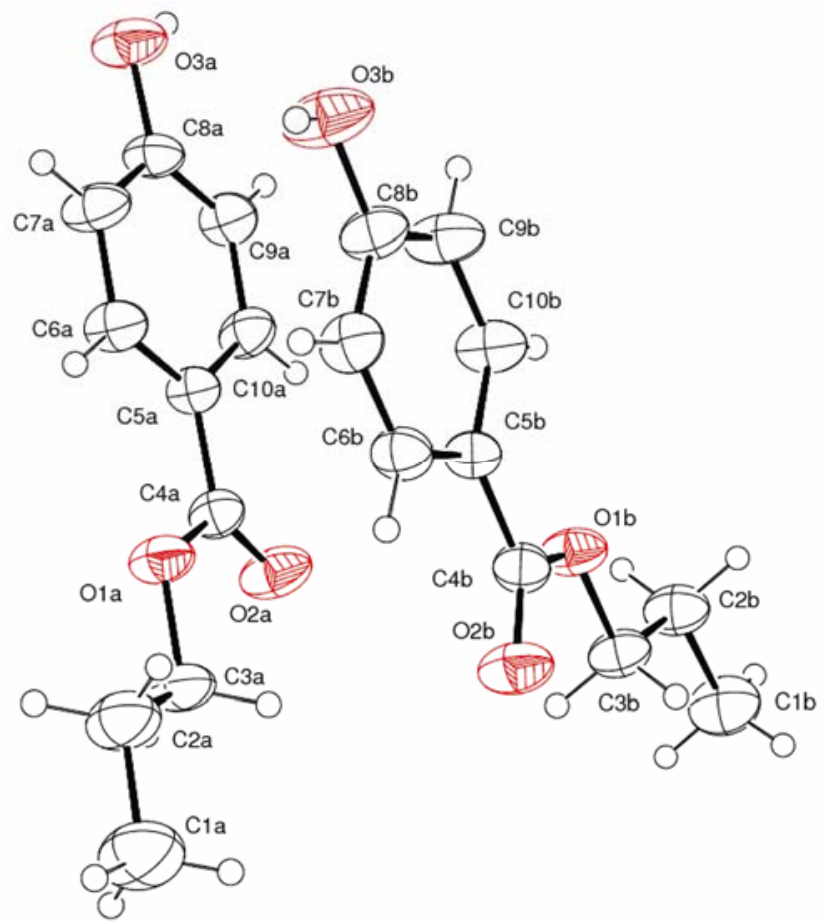

Figure 3. ORTEP view of the molecule. 


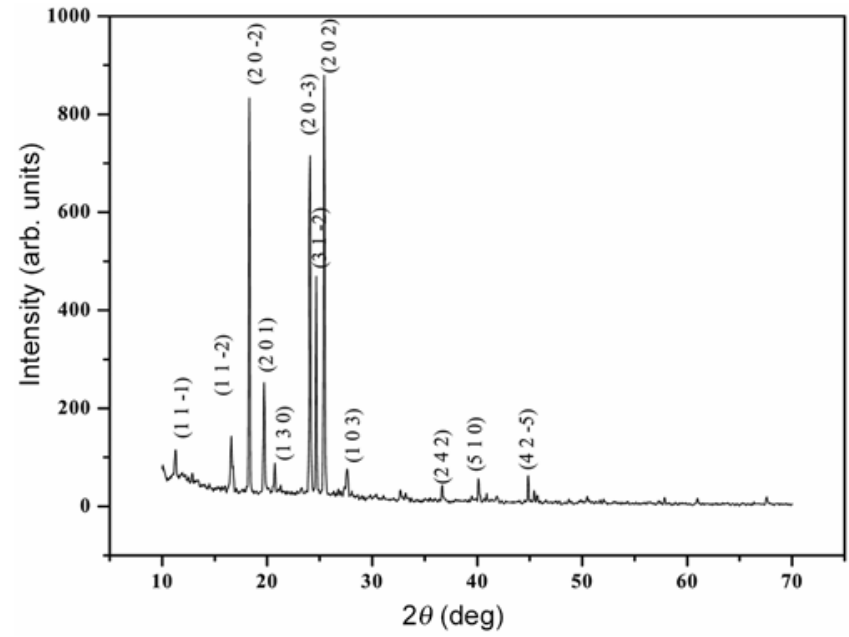

Figure 4. Powder X-ray diffractogram.

carried out. A multicrystal X-ray diffractometer (Lal and Bhagavannarayana 1989) was used to record highresolution rocking or diffraction curves (DCs). In this system, a fine focus $\left(0.4 \times 8 \mathrm{~mm}^{2} ; 2 \mathrm{~kW}\right.$ Mo $)$ X-ray source energized by a well-stabilized Philips $\mathrm{X}$-ray generator (PW 1743) was employed. The well-collimated and monochromated $\operatorname{MoK} \alpha_{1}$ beam obtained from the three monochromator Si crystals set in dispersive $(+,-,-)$ configuration has been used as the exploring $\mathrm{X}$-ray beam. This arrangement improves the spectral purity $\left(\Delta \lambda / \lambda \ll 10^{-5}\right)$ of the MoK $\alpha_{1}$ beam. The divergence of the exploring beam in the horizontal plane (plane of diffraction) was estimated to be $\ll 3$ arc sec. The specimen crystal is aligned in the $(+,-,-,+)$ configuration. Due to dispersive configuration of the third monochromator crystal with respect to the second monochromator, the spectral quality of the diffracted beam emerging from the third monochromator is highly perfect $\left(\Delta \lambda / \lambda \sim 10^{-5}\right.$; horizontal divergence $\gg 3$ arc sec) and, hence, though the lattice constant of the monochromator crystal and the specimen are different, the unwanted experimental dispersion broadening in the diffraction curve of the specimen crystal $\left(\Delta \mathrm{FWHM}=\Delta \lambda / \lambda\left(\tan \theta_{\mathrm{M}}-\tan \theta_{\mathrm{S}}\right) ; \theta_{\mathrm{M}}\right.$ and $\theta_{\mathrm{S}}$ being the Bragg diffraction angles of monochromator and the specimen crystals, respectively) is insignificant. The advantage of dispersion configuration $(+,-,-)$ over the non-dispersive configuration $(+,-,+)$ of monochromators is well described (Bhagavannarayana and Kushwaha 2010). The specimen can be rotated about a vertical axis, which is perpendicular to the plane of diffraction, with minimum angular interval of $0.4 \mathrm{arc}$ sec. The diffracted intensity is measured by using a scintillation counter. The DCs were recorded by changing the glancing angle (angle between the incident X-ray beam and the surface of the specimen) around the Bragg diffraction peak position, $\theta_{\mathrm{B}}$ (taken zero as reference point) starting from a suitable arbitrary glancing angle $(\theta)$. The detector was kept at the

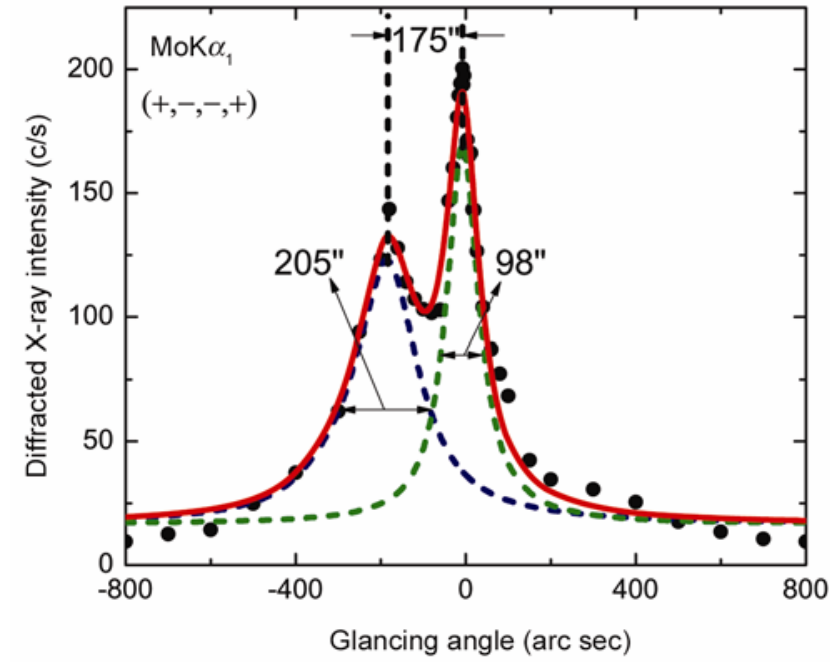

Figure 5. Rocking curve.

same angular position $2 \theta_{\mathrm{B}}$ with wide opening for its slit, the so-called $\omega$ scan (Bhagavannarayana and Kushwaha 2010). The omega scan is very appropriate to record the short-range order scattering caused by the defects or by the scattering from local Bragg diffractions from agglomerated point defects or due to low-angle and very-lowangle structural grain boundaries (Senthilkumar et al 2010). Before recording the diffraction curve, to remove the non-crystallized solute atoms, which remained on the surface of the crystal and also to ensure the surface planarity, the specimens were first lapped and chemically etched in a non-preferential etchant of water and acetone mixture in $1: 2$ volume ratio.

Figure 5 shows the high-resolution rocking curve (RC) recorded for a typical PHB specimen crystal using (202) diffracting planes in symmetrical Bragg geometry under the experimental conditions described above. As seen in the figure, the curve is not having a single diffraction peak. The solid line, which follows well with the experimental points (filled circles), is the convoluted curve of two peaks using the Lorentzian fit. The additional peak depicts an internal structural low-angle (tilt angle $\geq 1$ arc min, but less than a deg) boundary (Bhagavannarayana et al 2005) whose tilt angle (misorientation angle between the two crystalline regions on both sides of the structural grain boundary) is 75 arc sec from its adjoining region. The FWHM (full width at half maximum) of the main peak and the low-angle boundary are, respectively, 98 and 205 arc sec. The FWHM of the grain belonging to lowangle boundary is quite high, showing that this part of the crystal contains mosaic blocks misoriented to each other up to few tens of arc sec. Though the crystal contains a low-angle boundary, the low-angular spread of $\sim 1600$ arc sec of the DC indicates that the quality of the PHB crystal is fairly good. It may be mentioned here that such a low-angle boundary could be detected with well-resolved 
peak in the diffraction curve only because of the high resolution of the multicrystal X-ray diffractometer used in the present study.

\subsection{Chemical etching analysis}

The etching studies were carried out on the PHB single crystal on (1 01 1) plane to study the structural defects. It is known that the shapes of the etch pits can be different for different concentrations of etchant. Changes in the shapes of etching patterns are usually observed when chemical reactions are involved in the etching process. In chemical etching, the etching time, concentration of etchant (etchant ratio) and selective etchant are playing vital role (Ramesh Babu and Sethuraman 2007). When the crystal was etched for $10 \mathrm{~s}$, the elongated triangles like etch pits were observed. Randomly distributed, but strictly oriented pits are seen (figure 6). On successive etching for $25 \mathrm{~s}$, the triangle etch pits enlarge in size retaining their geometrical shape. To establish the selective action, the depth of the pits is increased and the pits are finally overlapped. Repetition for many times did not change the pits, which proves that these etch pits are of dislocation origin. Quality of the as-grown PHB crystal was quantitatively determined by the dislocation density measured by the etch pit counts per unit area $\left(\mathrm{cm}^{-2}\right)$ emerging on (l $\left.\begin{array}{lll}1 & 0 & 1\end{array}\right)$ plane. When a real crystal grows in an uncontrolled system, it will usually have a dislocation density of the order of $10^{8-10}$ lines $\mathrm{cm}^{-2}$ (Senthil Pandian et al 2012). Estimated etch pit density (EPD) was found to be $68.8 \times 10^{2} \mathrm{~cm}^{-2}$. This is a low EPD, which indicates that the grown crystal has smaller amount of dislocations.

\subsection{Optical studies}

3.6a UV-Vis-NIR transmission: Crystalline defects affect the optical properties such as light absorption,

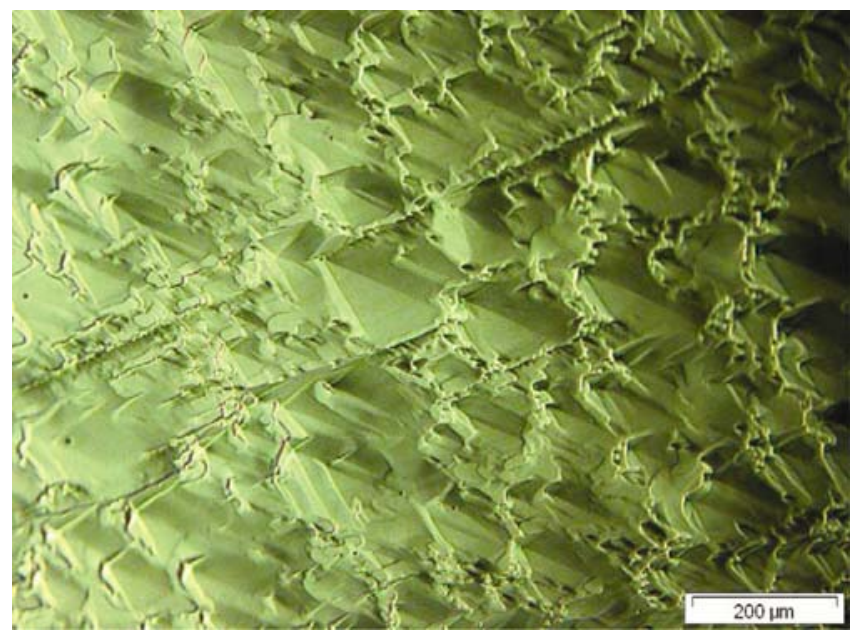

Figure 6. Etch pit pattern of PHB single crystals. scattering, refractive index and for practical application, crystals free from light scattering and absorbing defects are required. The improvement in the transmission percentage is due to lesser defects, which in turn decreases the scattering centres and increases the output intensity. The recorded spectrum is shown in figure 7 . The lower UV cut-off wavelength of the PHB single crystal is $304 \mathrm{~nm}$. The PHB single crystal has 55\% transmittance in the entire visible region. The optical transparency of organic single crystals of HA (Suresh Kumar and Rajendra Babu 2007), p-MHB (Vijayan et al 2003) and DBCH (Udaya Lakshmi and Ramamurthi 2005) is less than 50\%. The enhancement in the percentage of transmission may be attributed to a reduced scattering from structural and crystallographic defects (Senthil Pandian et al 2011).

3.6b Photoluminescence ( $P L$ ) analysis: The sample was excited at the wavelength of $350 \mathrm{~nm}$. There is no intense emission in the visible region as shown in figure 8. The maximum emission around $387 \mathrm{~nm}$ may be attributed to $\pi \rightarrow \pi^{*}$ and $n \rightarrow \pi^{*}$ transitions present in the PHB crystal. These transitions may be from $\mathrm{OH}$ and carbonyl groups. The emission spectrum intensity is low in the visible region because of the distortion to benzene ring with two substituted groups. One is electron acceptor, carbonyl group $\mathrm{C}=\mathrm{O}$ and the other being electron donor group, $\mathrm{OH}$. So the benzene ring is distorted and the rigid structure is influenced by the two groups and thereby reduces the emission intensity. The maximum emission $387 \mathrm{~nm}$ corresponds to the ultraviolet region.

3.6c Birefringence: Birefringence and refractive index are the most important material parameters for calculating phase matching angles (Fischer and Ohmer 1995) and to study the perfection of crystals. Birefringence is a characteristic of an optical material and is defined as a difference between effective refractive indices of ordinary

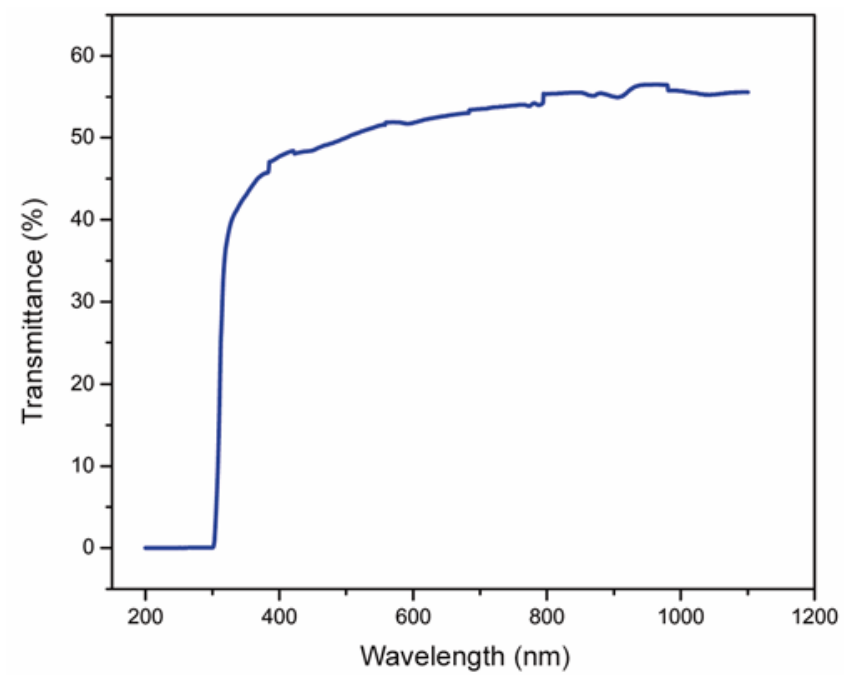

Figure 7. UV-Vis NIR transmission spectrum. 


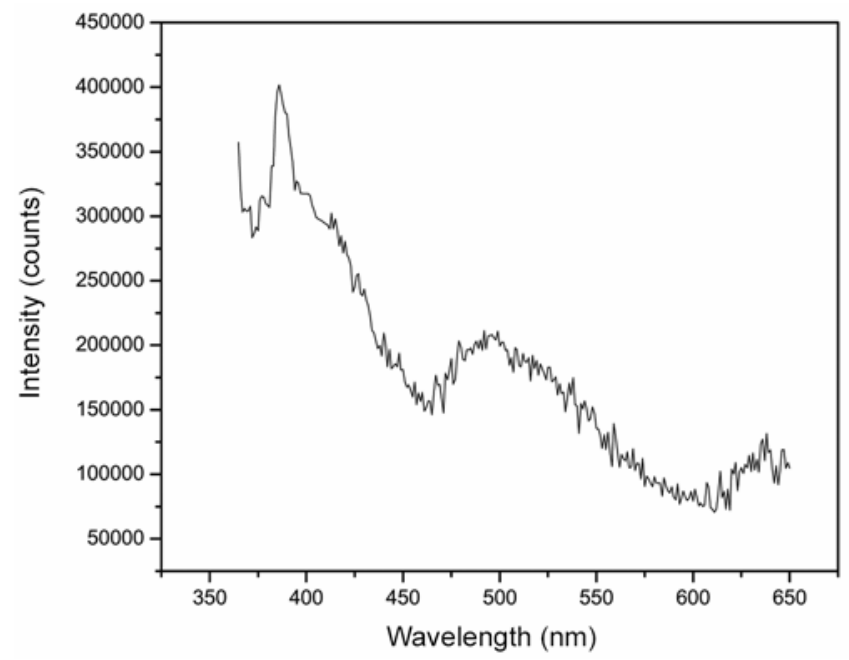

Figure 8. Photoluminescence emission spectrum.

and extraordinary rays. The mineral calcite also known as iceland spar is a widely used material in optics because of its birefringence. Its birefringence is so large that a calcite crystal placed over a line on a page will reveal two distinct images of the line. This characteristic behaviour may be used in birefringent crystal polarization devices. The birefringence value of calcite is 0.172 (Klocek Klocek and Paul Klocek 1991). The double refraction of PHB single crystal is shown in figure 9(a). The grown PHB single crystal was subjected to birefringence measurements using channeled spectrum method. The thickness of the sample used for the experiment is $0.185 \mathrm{~mm}$. We found that the value of birefringence lies between 0.08514 and 0.10148 in the wavelength region of 500 $600 \mathrm{~nm}$ as shown in figure 9(b).

The obtained values were found to be positive integers and decrease with increasing wavelength, which illustrated that the PHB possesses negative dispersion of birefringence and the curve shows crystal being optically positive at room temperature. The negative dispersion of materials can be used for the fabrication of a pair of prisms for the production of a net negative dispersion, which can be used to balance the positive dispersion of the laser medium (Fork et al 1984; Bhoopathi et al 2013). From this analysis, the highest value of PHB is $0 \cdot 10148$, which is higher than the other organic materials like benzophenone (0.0267) and benzimidazole (0.0962) at the same wavelength range (Vijayan et al 2007; Senthil Pandian et al 2012).

\subsection{Laser damage threshold}

For the LDT measurement, $1 \mathrm{~mm}$ diameter beam was focused on the sample. The multiple-shot LDT measurements were made on the PHB single crystal. The sample was irradiated at different spots on the same plane of
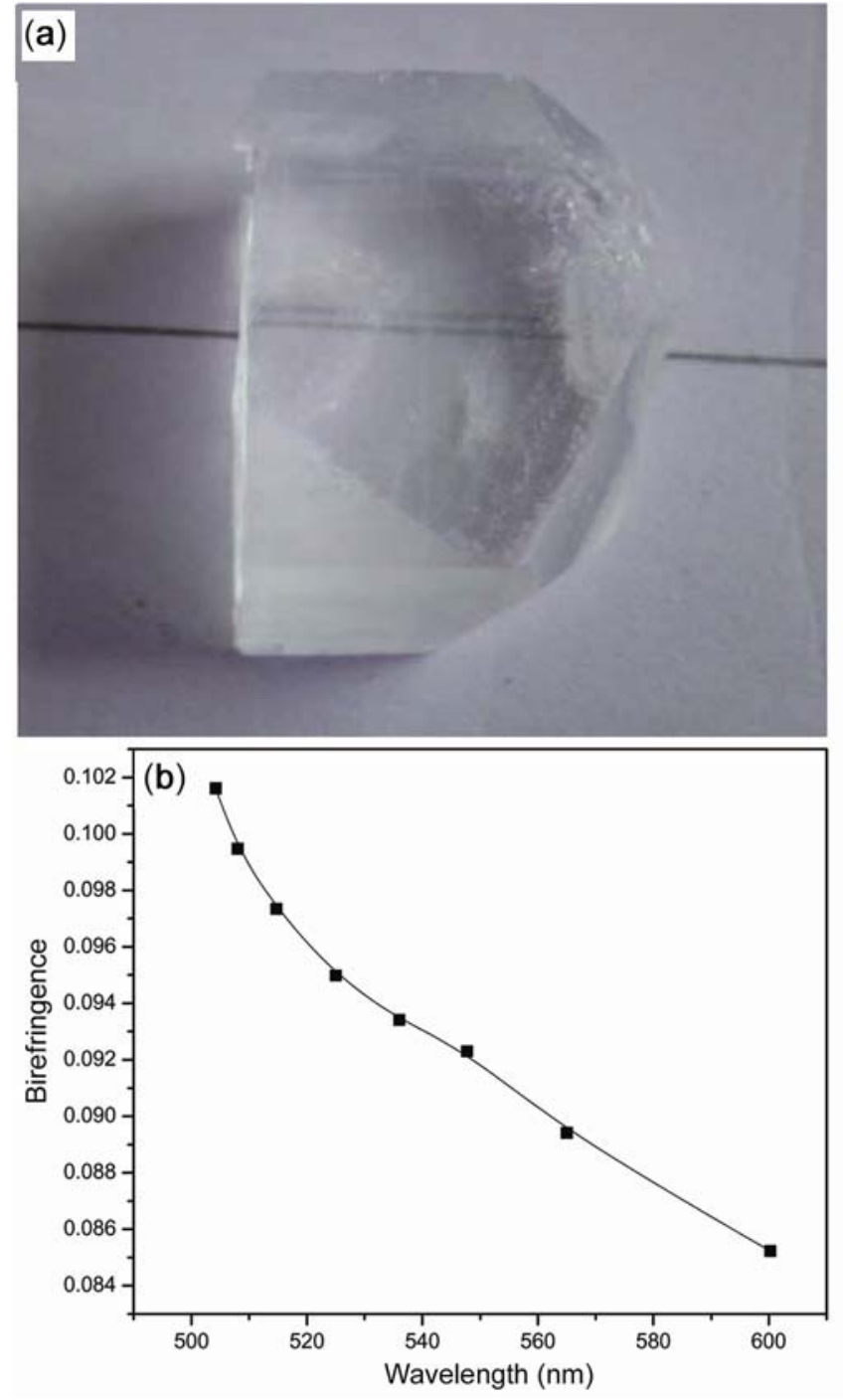

Figure 9. (a) Double refraction of PHB single crystal. (b) Birefringence of PHB single crystal.

similar experimental condition. In order to probe the nature of the damage, the PHB crystal was examined under an optical microscope. At the damage spot of PHB crystal, one can see a milky appearance and cracks, as shown in figure 10. The damage morphologies of material surface by nanosecond irradiation usually show a similar form as uneven and disordered surface structures consisting of melting and re-solidification at threshold condition (Senthil Pandian et al 2012). The power density was calculated as

$$
p_{\mathrm{d}}=\frac{E}{\tau \pi r^{2}}
$$

where $P_{\mathrm{d}}$ is the power density, $E$ the input energy in milli joules, $\tau$ the pulse width and $r$ the radius of the beam. The average LDT of PHB single crystal is $1.3 \mathrm{GW} / \mathrm{cm}^{2}$. Good value of LDT indicates that a grown crystal contains a low defect, which is in tune with less EPD. 


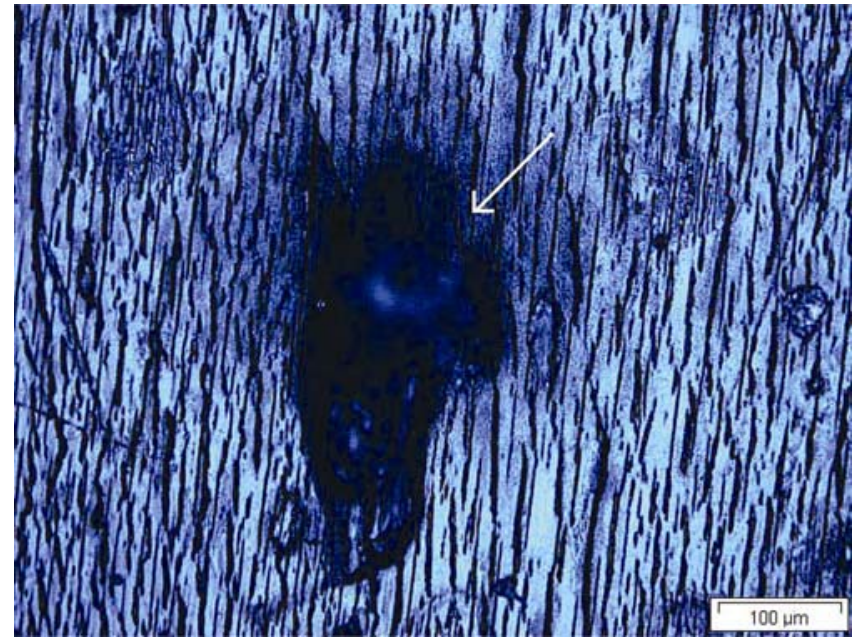

Figure 10. Laser damage pattern.

\subsection{Vickers microhardness}

Hardness is a complex property related to the extent to which solids resist both elastic and plastic deformations. Experimentally, its value is measured by the indentation size after a hard indenter has deformed a material. At the microscopic level, the hardness of an ideal solid depends on the nature of its chemical bonding (Keyan et al 2008). The size of the crystal subjected to the experiment was $10 \times 10 \times 5 \mathrm{~mm}^{3}$. The indentation was made for the applied load in the range of 10, 25, 50 and $100 \mathrm{~g}$. After this process, the permanent impression left by the indenter was measured and the hardness value was calculated. The Vickers diamond pyramid indenter is grounded in the form of a squared pyramid with an angle of $136^{\circ}$ between faces. When calculating the Vickers hardness number, both diagonals of the indenter are measured and the mean of these values are used in the given formula with the load used to determine the value of $H_{\mathrm{v}}$

$$
\begin{aligned}
& H_{\mathrm{v}}=\frac{2 P \sin \left(136^{\circ} / 2\right)}{d^{2}}, \\
& H_{\mathrm{v}}=1.854 \frac{P}{d^{2}},
\end{aligned}
$$

where $P$ is the applied load in $\mathrm{kg}, d$ the mean of the diagonals, $d_{1}$ and $d_{2}$ in $\mu \mathrm{m}, H_{\mathrm{v}}$ Vickers hardness number. Figure 11 shows the variation of $P$ with Vickers hardness number $\left(H_{\mathrm{v}}\right)$ for PHB single crystal. The hardness value of PHB crystal is $39 \mathrm{~kg} / \mathrm{mm}^{2}$ in the load of $10 \mathrm{~g}$, while it goes up to $54 \mathrm{~kg} / \mathrm{mm}^{2}$ when $100 \mathrm{~g}$ of load is used. PHB single crystal has good mechanical hardness, compared to other organic crystals such as B2AM $\left(37 \mathrm{~kg} / \mathrm{mm}^{2}\right.$ when $100 \mathrm{~g}$ of load used), $2 \mathrm{~A}-5 \mathrm{CB}\left(26.8 \mathrm{~kg} / \mathrm{mm}^{2}\right.$ when $100 \mathrm{~g}$ of load used) and HA (39 kg/mm² when $100 \mathrm{~g}$ of load used) (Boomadevi and Dhanasekaran 2004; Mohamed et al 2007; Dhanaraj et al 2010). The LDT of the crystal

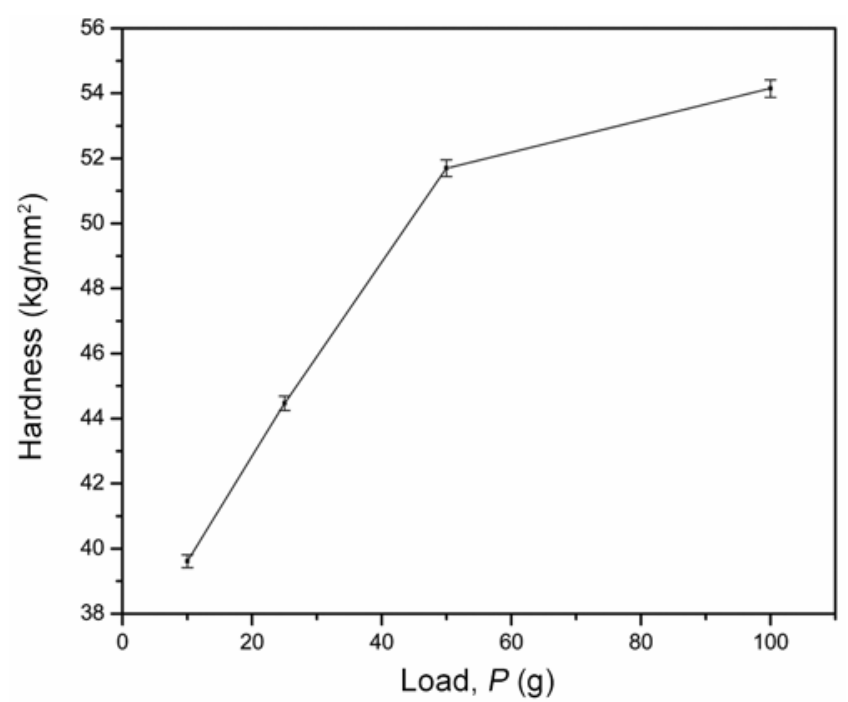

Figure 11. Plot of Vickers microhardness number.

also plays a vital role in the hardness and is directly correlated to $H_{\mathrm{v}}$. The higher mechanical hardness for PHB crystal will have a significant effect on organic application, handling and processing such as ease in polishing and less wastage due to the breakage, while processing steps for fabrication of devices.

\subsection{Dielectric tensor analysis}

Dielectric properties are correlated with the electro-optic property of the crystals (Meena and Mahadevan 2008). The magnitude of dielectric permittivity depends on the degree of polarization charge displacement in the crystals. The dielectric permittivity of the material is due to the contribution of electronic, ionic, dipolar and space charge polarizations which depends on frequencies. At low frequencies, all the polarizations are active (Miller 1964).

The dielectric measurement was carried out using the instrument HIOKI 3532-50 LCR HITESTER. The method described in Fapeng Yu et al (2010) was used to determine dielectric tensors. The PHB single crystal was cut and $1 \mathrm{~mm}$ thick plates were prepared. Dielectric permittivities were determined for the $X, Y, Z$ cut samples. The sample was electroded on either side with silver coating to make it behave like a parallel plate capacitor. The dielectric permittivity of a crystalline material is a secondrank tensor. For a monoclinic system, there are four independent components. Anisotropy in the dielectric behaviour has been observed. The dielectric tensor for PHB single crystal was determined as a function of temperature at $1 \mathrm{kHz}$ frequency (figure 12a).

Figure 12(b) shows the dielectric loss of the PHB single crystal for various temperatures at various frequencies. At higher frequencies, it is noted that the dielectric loss is 

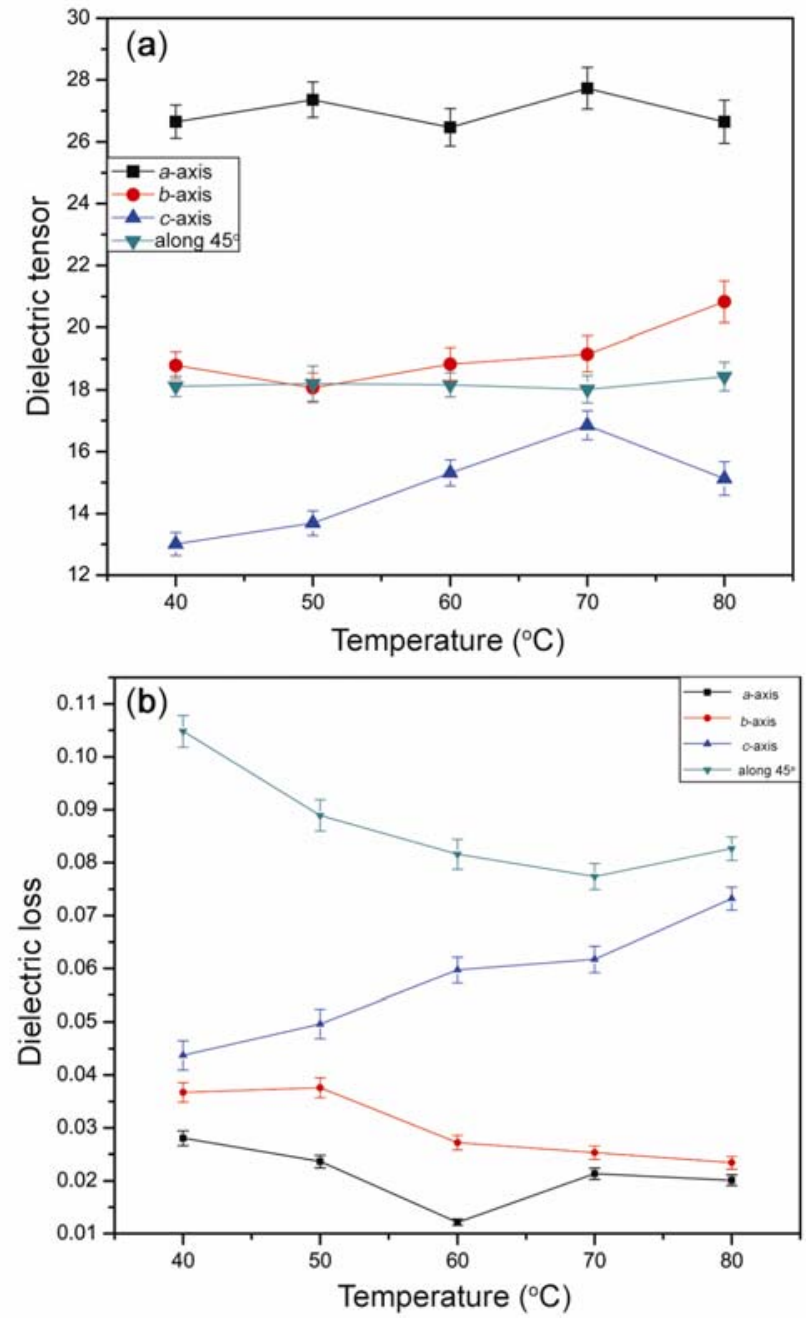

Figure 12. (a) Dielectric tensor components. (b) Temperature-dependent dielectric loss.

very low. It has been considered that the dielectric losses at low frequencies have nothing in common with the fundamental lattice properties and are fully determined by defects and impurities (Keyan et al 2008; Senthil Pandian et al 2012).

\subsection{Thermal analysis}

To check the thermal stability of the material, differential thermal analysis (DTA) as well as thermogravimetric analysis (TGA) were carried out. TGA is a type of testing performed on samples that determines changes in weight in relation to change in temperature. The measurements exhibit single-stage weight loss between 150 and $290^{\circ} \mathrm{C}$. This may be due to the decomposition of PHB crystal. There is no weight loss observed below $150{ }^{\circ} \mathrm{C}$. The DTA of PHB was also performed between 25 and $500{ }^{\circ} \mathrm{C}$ in nitrogen atmosphere at a heating rate of $10^{\circ} \mathrm{C} / \mathrm{min}$. In DTA, there is a sharp endothermic peak at $99{ }^{\circ} \mathrm{C}$, which corresponds to the melting point of the crystal (figure 13).

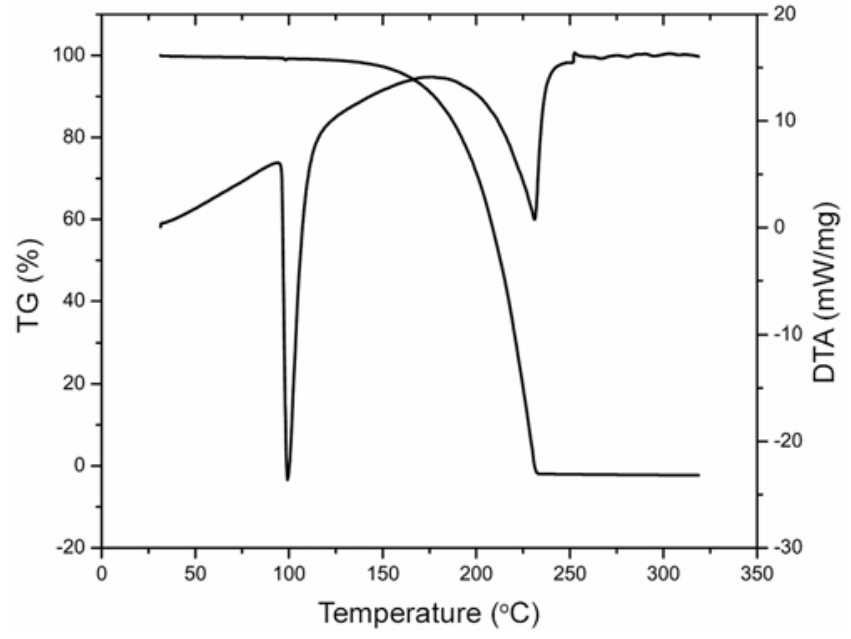

Figure 13. Thermogravimetric-differential thermal analysis curve.

\section{Conclusions}

A single crystal of propyl-p-hydroxybenzoate was grown by slow evaporation solution technique. The presence of various functional groups was confirmed by using FT-IR and FT-Raman spectroscopy studies. Single-crystal Xray diffraction studies show that $\mathrm{PHB}$ belongs to monoclinic system with space group $P 21 / c$. The crystalline perfection of the as-grown single crystal was evaluated by high-resolution X-ray diffraction (HRXRD) analysis. It reveals that the crystalline perfection is good. The crystal has $55 \%$ of transparency in the entire visible region. The photoluminescence of PHB single crystal has maximum intensity at $387 \mathrm{~nm}$, which corresponds to ultraviolet emission. The birefringence value is found to be $0 \cdot 10148$ at the wavelength of $504 \mathrm{~nm}$. The birefringence value of PHB single crystal indicates good optical homogeneity. The laser damage threshold was measured and the value is $1.3 \mathrm{GW} / \mathrm{cm}^{2}$. No cracks have been observed up to $100 \mathrm{~g}$ of load and the hardness value of PHB single crystal at $100 \mathrm{~g}$ is $54 \mathrm{~kg} / \mathrm{mm}^{2}$. The dielectric permittivity and dielectric loss were studied. The low values of dielectric loss indicate that the grown PHB single crystal contains minimum defects and good quality.

\section{Supplementary material}

CCDC 840828 contains the supplementary crystallographic data for this paper. These data can be obtained free of charge from the Cambridge Crystallographic Data Centre via www.ccdc.cam.ac.uk/data_request/cif.

\section{Acknowledgements}

The authors are thankful to Prof G Bhagavannarayana, Materials Characterization Division, NPL, New Delhi, for 
HRXRD measurements, Dr S Nagarajan, PSG Arts and Science College, Coimbatore, for birefringence measurements and Prof S Kalainathan, School of Science, VIT, Tamil Nadu for providing microhardness studies, laser damage threshold and dielectric studies.

\section{References}

Abdul Kareem Parchur, Raghumani Singh Ningthoujam and Shyam Bahadur Rai 2011 Dalton Trans. 407595

Avanesjan O S, Benderskii V A, Brikenstein V K, Broude V L, Korshunov L I, Lavrushko L A G and Tartakovskii I I 1974 Mol. Cryst. Liq. Cryst. 29165

Bhagavannarayana G, Ananthamurthy R V, Budakoti G C, Kumar B and Bartwal K S 2005 J. Appl. Cryst. 38768

Bhagavannarayana G and Kushwaha S K 2010 J. Appl. Cryst. 43154

Berggren M, Dodabalapur A, Slusher R E and Bao Z N 1997 Nature 389466

Bhoopathi G, Jayaramakrishnan V, Ravikumar K, Prasanyaa T and Karthikeyan S 2013 Mater. Sci. Poland 311

Boomadevi S and Dhanasekaran R 2004 J. Cryst. Growth 261 70

Briseno A L, Mannsfeld S C B, Ling M M, Liu S, Tseng R J, Reese C, Roberts M E, Yang Y, Wudl F and Bao Z N 2006 Nature $\mathbf{4 4 4} 913$

Butko V Y, Chi X and Ramirez A P 2003 Solid State Commun. 128431

De Boer R W I, Gershenson M E, Morpurgo A F and Podzorov V 2004 Phys. Status Solidi A201 1302

Dhanaraj P V, Rajesh N P and Bhagavannarayana G 2010 Physica B 4053441

Fang X N, Chen W T, Xu Y P, Luo Q Y and Chen H L 2009 J. Iran. Chem. Soc. 6213

Fapeng Yu, Shujun Zhang, Xian Zhao, Duorong Yuan, ChunMing Wang and Thomas R Shrout 2010 Cryst. Growth Des. 1871

Farrugia L J 1999 ORTEP-3 for Windows (Scotland, UK: University of Glasgow)

Ferdinando Giordano, Ruggero Bettini and Cristina Donini 1999 J. Pharm. Sci. 881210

Fichou. D, Delysee S and Nunzi J M 1997 Adv. Mater. 91178

Fischer D W and Ohmer M C 1995 J. Appl. Phys. 775942

Fork R L, Martinez O E and Gordon J P 1984 Opt. Lett. 9150

Hide F, Diaz-Garcia M, Schwartz B J, Andersson M, Pei Q and Heeger A J 1996 J. Sci. 2731833

Hisao Y, Takayuki M and Hotta S 2002 Appl. Phys. Lett. 81 1512

Ichikawa M, Hibino R, Inoue M, Haritani T, Hotta S, Koyama T and Taniguchi Y 2003 Adv. Mater. 15213

Karunagaran N and Ramasamy P 2012 AIP Conf. Proc. 1447 1291

Keyan Li, Xingtao Wang, Fangfang Zhang and Dongfeng Xue 2008 Phys. Rev. Lett. 100235504
Klocek Klocek and Paul Klocek 1991 Handbook of infrared optical materials p 143

Kok Y, Masaaki Y and Masahiro H 2006 Appl. Phys. Lett. 88 083511

Lal K and Bhagavannarayana G 1989 J. Appl. Cryst. 22209

Ma D G and Ma Y G 2005 J. Am. Chem. Soc. 12714152

Mannsfeld S C B, Locklin J, Reese C, Roberts M E, Lovinger A J and Bao Z N 2007 Adv. Funct. Mater. 171617

Meena M and Mahadevan C K 2008 Cryst. Res. Technol. 43 166

Miller R C 1964 Appl. Phys. Lett. 517

Mohamed M G, Rajarajan K, Mani G, Vimalan M, Prabha K, Madhavan J and Sahayaraj P 2007 J. Cryst. Growth 300409

Musubu I, Kiyoshi N, Masamitsu I and Yoshio T 2005 Appl. Phys. Lett. 87221113

Parchur A K, Prasad A I, Ansari A A, Rai S B and Ningthoujam R S 2012a Dalton Trans. 4111032

Parchur A K and Ningthoujam R S 2012b RSC Adv. 210859

Pope M, Kallmann H P and Mangnante P 1963 J. Chem. Phys. 382042

Ramesh Babu R and Sethuraman K 2007 Mater. Lett. 613480

Reese C and Bao Z N 2006 J. Mater. Chem. 16329

Senthilkumar K, Moorthy Babu S and Bhagavannarayana G 2010 J. Appl. Cryst. 44313

Senthil Pandian M, Pattanaboonmee N, Ramasamy P and Manyum P 2011 J. Cryst. Growth 314207

Senthil Pandian M, Boopathi K, Ramasamy P and Bhagavannarayana G 2012 Mater. Res. Bull. 47826

Senthil Pandian M and Ramasamy P 2012 Mater. Chem. Phys. 1321019

Sheldrick G M, SHELX97 1997 Program for the crystal structure refinement (Germany: University of Gottingen)

Sundar V C, Zaumseil J, Podzorov V, Menard E, Willett R L, Someya T, Gershenson M E and Rogers J A 2004 Science 3031644

Suresh Kumar B and Rajendra Babu K 2007 Cryst. Res. Technol. 42607

Takenobu T, Bisri S Z, Takahashi T, Yahiro M, Adachi C and Iwasa1 Y 2008 Phys. Rev. Lett. 100066601

Tessler N, Denton G J and Friend R H 1996 Nature 382695

Tessler N 1999 Adv. Mater. 11363

Tseng R J, Chan R, Tung V C and Yang Y 2008 Adv. Mater. 20 435

Udaya Lakshmi K and Ramamurthi K 2005 Cryst. Res. Technol. 401165

Vijayan N, Ramesh Babu R, Gunasekaran M, Gopalakrishnan R and Ramasamy P 2003 J. Cryst. Growth 256174

Vijayan N, Nagarajan K, Alex, Slawin M Z, Shashidharan Nair C K and Bhagavannarayana G 2007 Cryst. Growth Des. 7 445

Xie Z Q, Yang B, Cheng G, Liu L L, He F, Shen F Z, Ma Y G and Liu S Y 2005 Chem. Mater. 171287

Xie Z Q, Xie Yang B, Cheng G, Liu L L, Yang G D, Xu H, Ye L Hanif M, Liu S Y, Yanagi H, Ohara T and Morikawa T 2001 Adv. Mater. 131452 